\title{
Radiofrequency catheter ablation of accessory pathways in infants
}

\author{
Fernando Benito, Cristina Sánchez
}

\begin{abstract}
Objective-To evaluate the indications, results and complications of radiofrequency catheter ablation in small infants with supraventricular tachycardia due to an accessory atrioventricular pathway. Methods-Five infants less than 9 months old underwent radiofrequency catheter ablation of accessory pathways. Ablation was done for medically refractory tachyarrhythmia associated with aborted sudden death in two patients, left ventricular dysfunction in one, failure of antiarrhythmic drugs in one, and planned cardiac surgery in one. All five patients underwent a single successful procedure. Three left free wall pathways were ablated by transseptal approach, a right posteroseptal pathway was ablated from the inferior vena cava, and a left posteroseptal pathway was approached from the inferior vena cava into the coronary sinus. A deflectable 5F bipolar electrode catheter with a $3 \mathrm{~mm}$ tip was used.

Results-A sudden increment in impedance indicative of coagulum formation was observed in two procedures. One patient developed a transient ischaemic complication after ablation of a left lateral accessory pathway by transseptal approach. This patient had mild pericardial effusion after the procedure. Moderate pericardial effusion was also noted in another patient. After a mean follow up of 18.4 months all patients are symptom free without treatment.

Conclusions-Radiofrequency catheter ablation can be performed successfully in infants. Temperature monitoring in $5 F$ ablation catheters would be desirable to prevent the development of coagulum. Echocardiography must be performed after the ablation procedure to investigate pericardial effusion.
\end{abstract}

(Heart 1997;78:160-162)

Arrhythmia Unit, Department of Paediatric Cardiology, Hospital Infantil La Paz, Madrid, Spain

F Benito

C Sánchez

Correspondence to: Dr F Benito, Meléndez Valdés $22,5^{\circ} \mathrm{B}, 28015$ Madrid, Spain.

Accepted for publication 25 October 1996

Radiofrequency catheter ablation has established as a highly effective and safe technique for eliminating accessory atrioventricular (AV) connections in adults and children. ${ }^{1-4}$ However, early results suggest that this technique should be avoided in infants because of possible procedure related mortality and the risk of unknown long term effects of radiofrequency lesions on the immature myocardium and the coronary arteries. ${ }^{5-7}$ We report our experience with radiofrequency catheter ablation in small infants.

\section{Methods}

Between November 1993 and June 1995, 45 children younger than 20 years underwent radiofrequency ablation of accessory pathways in our Institution. Of these, five patients were infants aged less than 9 months.

\section{PATIENTS}

The patients were one boy and four girls, ranging in age from 2.5 to 8 months, mean (SD) $4 \cdot 2(2 \cdot 2)$, with an average weight of $5 \cdot 4$ $\mathrm{kg}$ (range $3 \cdot 5$ to $9 \cdot 0$ ). Clinical characteristics of the patients are given in the table. The primary indication for the ablation was aborted sudden death associated with WolffParkinson-White syndrome and medically refractory supraventricular tachycardia in two patients, left ventricular dysfunction due to incessant tachycardia in one patient, failure of antiarrhythmic drugs in one patient who had tuberous sclerosis with multiple cardiac rhabdomyomas, and planned cardiac surgery in one patient who had a double outlet right ventricle.

\section{ELECTROPHYSIOLOGICAL STUDY}

Informed consent was obtained from the parents in all cases. Electrophysiological studies were performed under either general anaesthesia (two patients) or sedation with midazolam and fentanyl (three patients). Pulse oximetry was monitored continuously during the study. Three $5 \mathrm{~F}$ electrode catheters were inserted into the femoral veins and the internal jugular or subclavian vein and were advanced under fluoroscopic guidance to the high lateral right atrium, the right ventricular apex, the His bundle position, and the coronary sinus. Because of the small vein size in infants, a single electrode catheter was used for right atrial recording/pacing and right ventricular pacing. A diagnostic study was performed to determine the electrophysiological features of the accessory AV connections, the tachycardia mechanisms, and the location of the accessory AV pathways.
CATHETER ABLATION

After initial localisation, precise mapping was performed using a deflectable $5 \mathrm{~F}$ bipolar electrode catheter with a $3 \mathrm{~mm}$ tip (Mansfield/ 
Patient data and ablation results

\begin{tabular}{|c|c|c|c|c|c|c|c|c|c|c|c|c|c|}
\hline $\begin{array}{l}\text { Case } \\
\text { No }\end{array}$ & $\begin{array}{l}\text { Age } \\
\text { (months) }\end{array}$ & $\begin{array}{l}W t \\
(\mathrm{~kg})\end{array}$ & Diagnosis & Drugs & $\begin{array}{l}\text { Associated } \\
\text { cardiac } \\
\text { problems }\end{array}$ & Indications & $\begin{array}{l}\text { Acc path } \\
\text { location }\end{array}$ & $\begin{array}{l}C L \\
(m s)\end{array}$ & Appl & $\begin{array}{l}\text { Duration } \\
\text { (s) }\end{array}$ & $\begin{array}{l}\text { Procedure } \\
\text { time (h) }\end{array}$ & $\begin{array}{l}\text { Fluorosc } \\
\text { time } \\
\text { (min) }\end{array}$ & $\begin{array}{l}\text { Follow up } \\
\text { (months) }\end{array}$ \\
\hline 1 & 3 & 4.5 & $\begin{array}{l}\text { PJRT } \\
\text { WPW/ }\end{array}$ & $\mathrm{D}, \mathrm{A}$ & $\mathrm{DC}$ & LVD,RA & LPS & 280 & 1 & 60 & 3 & 24 & 30 \\
\hline 2 & $4 \cdot 5$ & $3 \cdot 3$ & $\begin{array}{l}\text { WPW/ } \\
\text { OST }\end{array}$ & $\mathrm{D}, \mathrm{P}, \mathrm{A}$ & DORV & PCS & RPS & 220 & 3 & 15 & 5 & 25 & $17 \cdot 5$ \\
\hline 3 & 8 & 9 & $\begin{array}{l}\text { CAP/ } \\
\text { OST }\end{array}$ & $\mathrm{D}, \mathrm{S}, \mathrm{A}$ & CR & RA & LL & 250 & 7 & 60 & 5 & 53 & 18 \\
\hline 4 & $2 \cdot 5$ & $5 \cdot 3$ & $\begin{array}{l}\text { WPW/ } \\
\text { OST }\end{array}$ & $\mathrm{D}, \mathrm{A}$ & None & ASD,RA & LL & 240 & 1 & 60 & 2.75 & 25 & 13 \\
\hline 5 & 3 & 5 & $\begin{array}{l}\text { WPW/ } \\
\text { OST/ } \\
\text { AST }\end{array}$ & $\mathrm{D}, \mathrm{A}, \mathrm{P}, \mathrm{Pr}$ & None & ASD,RA & LP & 240 & 1 & 45 & $2 \cdot 25$ & 27 & $13 \cdot 5$ \\
\hline
\end{tabular}

A, amiodarone; Acc path location, accessory pathway location; Appl, number of radiofrequency applications; ASD, aborted sudden death; AST, antidromic supraventricular tachycardia; CAP, concealed accessory pathway; CL, cycle length of supraventricular tachycardia; CR, cardiac rhabdomyomas; D, digoxin; DC,
dilated cardiomyopathy; DORV, double outlet right ventricle; Fluorosc time, total fluoroscopy time; LI, left lateral; LP, left posterior; LPS, left posteroseptal; LVD, left ventricular dysfunction; OST, orthodromic supraventricular tachycardia; P, propafenone; PCS, planned cardiac surgery; PJRT, permanent form of junctional reciprocating tachycardia; Pr, propranolol; RA, refractory to antiarrhythmic drugs; RPS, right posteroseptal; S, sotalol; WPW, Wolff-Parkinson-White syndrome.

Webster). All patients were given a $100 \mathrm{IU} / \mathrm{kg}$ bolus of heparin after catheter placement, with repeat doses of $25 \mathrm{IU} / \mathrm{kg}$ each hour.

RF electrical current was generated by a voltage controller device (Medtronic CardioRhythm, 0610E Atakr ablation system) and was delivered for $25 \mathrm{~W}$ power. If the pathway conduction continued after 10 seconds or an abrupt increment in impedance was observed, the discharge was stopped and the catheter removed.

The procedure was considered successful when the tachycardia and pathway conduction were absent and could not be induced by programmed stimulation 30 minutes after the ablation trial, with and without isoprenaline infusion.

\section{FOLLOW UP}

The patients were monitored with continuous ECG display for 24 hours. In all patients an echocardiogram was done immediately after the procedure. Aspirin ( $5 \mathrm{mg} / \mathrm{kg}$ ) was given daily for six weeks for antiaggregation: A surface electrocardiogram and an echocardiogram were done at follow up.

\section{Results}

Results are given as mean (SD).

ELECTROPHYSIOLOGICAL STUDY

All patients had a unique accessory AV pathway. Three accessory pathways were located in the free wall of the left ventricle and two were posteroseptal. There were three manifest and two concealed accessory AV pathways. One of the concealed pathways had slow conduction time and decremental properties (the permanent form of junctional reciprocating tachycardia). The tachycardia cycle length was 246 (21) ms. Patient 1 had incessant tachycardia during electrophysiological study. Antidromic reciprocating tachycardia was only induced in patient 5

\section{CATHETER ABLATION}

The five patients underwent a single successful procedure. The ablation data of the patients are summarised in the table. The approach for the right sided pathway was from the right inferior vena cava. The three left free wall pathways were ablated by transseptal approach (one by transseptal puncture, two through a patent foramen ovale) (figure). The left posteroseptal pathway was approached from the right femoral vein into the coronary sinus. For successful ablation $2 \cdot 6(2 \cdot 1)$ radiofrequency applications were required, but only one application per patient was longer than 10 seconds. The duration of radiofrequency applications for successful ablation was 48 (19) s. A sudden rise in impedance indicative of coagulum formation was observed in two patients. Total procedure time was $3.6(1.3)$ hours (range 2.2 to 5) with a total fluoroscopy time of $30 \cdot 8$ $(12 \cdot 4)$ minutes.

\section{COMPLICATIONS}

A complication of the procedure occurred in two patients. Patient 3 developed ST segment
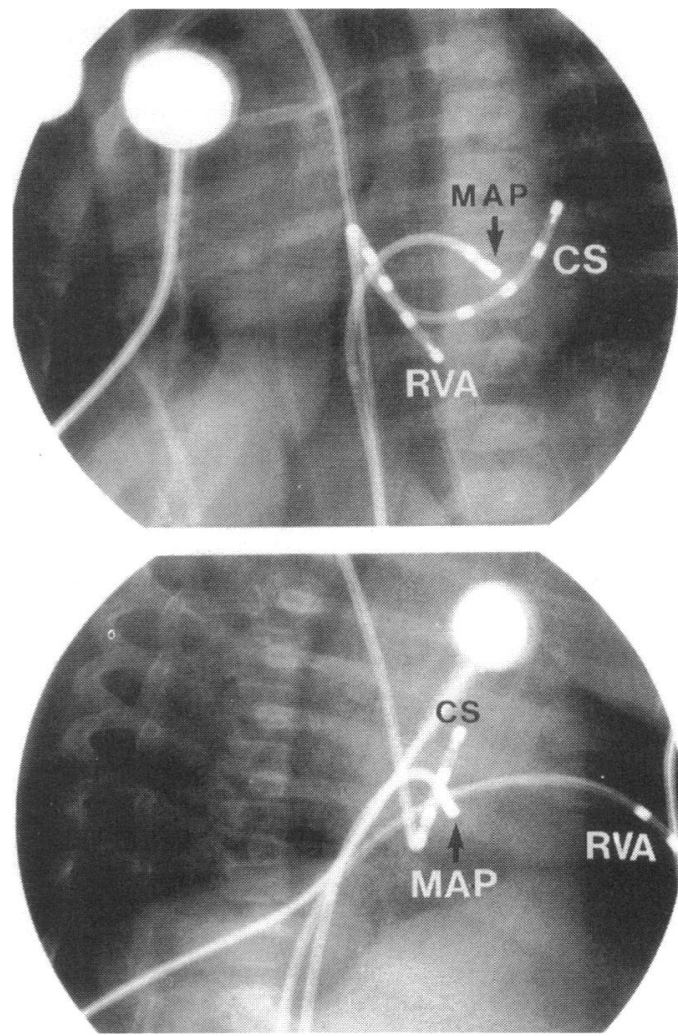

Chest radiographs of catheter electrode position during ablation of a left posterior pathway in patient 5. The ablating catheter is positioned by transseptal approach at the mitral annulus, in close proximity to the third electrode of the coronary sinus catheter. Left anterior oblique projection is shown in top panel and right anterior oblique is shown in bottom panel. $C S$, coronary sinus catheter; $M A P$, ablation/mapping catheter; RVA, right ventricular apex catheter. 
elevation in diaphragmatic leads and second degree AV block after delivery of radiofrequency current at the atrial side of the mitral annulus, during ablation of a left lateral accessory pathway. An isoprenaline infusion was given. Coronary arteriography done after haemodynamic improvement showed patent coronary arteries. The electrocardiographic abnormalities resolved spontaneously $15 \mathrm{~min}$ utes later. A mild pericardial effusion was noted by echocardiography after the procedure. The echocardiogram performed after ablation in patient 2 also showed a moderate pericardial effusion which resolved spontaneously. No other complications were observed.

\section{FOLLOW UP}

After a mean follow up of $\mathbf{1 8 . 4}$ months (range 13 to 30 ) all patients were symptom free without medication. No delta wave had recurred. Patient 1, who had developed a tachycardia induced cardiomyopathy with a shortening fraction of $20 \%$, had a progressive improvement of ventricular function with a shortening fraction of $30 \%$ one week after ablation. This patient has been reported on before. ${ }^{8}$ Follow up coronary arteriography was not performed in patient 3 .

\section{Discussion}

When necessary, radiofrequency catheter ablation can be performed in infants with acceptable success and complication rates. ${ }^{3569-11}$ However, because of low weight does carry potential risks, radiofrequency ablation should only be considered in very special circumstances, bearing in mind technical issues, potential immediate and long term complications, radiation exposure, and the unknown future of the lesion created. ${ }^{5-7} 12$ Our series illustrates the rare situations that may warrant catheter ablation in infants.

Extreme caution is required with the method used for ablation in infants. ${ }^{67}$ To minimise lesion size, a $5 \mathrm{~F}$ catheter with a $3 \mathrm{~mm}$ tip was used. A sudden increment in impedance during radiofrequency application was observed in two patients due to the development of a coagulum on the electrode tip. Closed loop temperature control, which is currently unavailable in a $5 \mathrm{~F}$ catheter, could prevent the development of coagulum. ${ }^{13}$

One patient developed a transient ischaemic complication after delivery of radiofrequency current during ablation of a left lateral accessory pathway by the transseptal approach. ST segment elevation in the diaphragmatic leads with second degree AV block suggested an acute ischaemic lesion of the right coronary artery. Angiography showed right dominant circulation and patent coronary arteries. This is the first transient ischaemic complication described in children. Lesh et al reported one episode of temporary ischaemia due to a coronary air embolism in an adult patient, associated with changing catheters through the
Müllins sheath after a transseptal puncture. ${ }^{14}$ Calkins et al described an ischaemic-but also transient-complication in another adult patient after delivery of radiofrequency current, which was probably caused by coronary artery spasm. ${ }^{1}$ Although the complication in our patient did not occur after catheter manipulation, both explanations are conceivable. Future studies will assess whether ablation in young patients involves a greater risk for the coronary arteries than in older patients. A pericardial effusion was noted immediately after ablation in two patients and resolved spontaneously. These data suggest that echocardiography must be performed after catheter ablation in all small patients.

\section{CONCLUSIONS}

(1) Although radiofrequency catheter ablation has an increase complications risk in infants, this technique can be performed successfully when no therapeutic alternative exists. (2) Temperature monitoring in the $5 \mathrm{~F}$ ablation catheters would be desirable to prevent the development of coagulum. (3) Echocardiography must be performed immediately after the ablation procedure in infants because of the possibility of pericardial effusion.

1 Calkins H, Langberg J, Sousa J, El-Atassi R, Leon A, Kou $\mathrm{W}$, et al. Radiofrequency catheter ablation of accessory atrioventricular connections in 250 patients. Abbreviated therapeutic approach to Wolff-Parkinson-White syndrome. Circulation 1992;85:1337-46.

2 Dick McD, O Connor BK, Serwer GA, Le Roy S, Armstrong $B$. Use of radiofrequency current to ablate accessory connections in children. Circulation 1991;84 2318-24.

3 Van Hare GF, Lesh MD, Scheinman M, Langberg JJ. Percutaneous radiofrequency catheter ablation for supraventricular arrhythmias in children. $\mathcal{f} \mathrm{Am}$ Coll Cardiol 1991;17:1613-20.

4 Van Hare GF, Witherell CL, Lesh MD. Follow-up of radiofrequency catheter ablation in children. Results in 100 consecutive patients. 7 Am Coll Cardiol 1994;23 1651-9.

5 Kugler JD, Danford DA, Deal BJ, Gillette PC, Perry JC, Silka MJ, et al, for the Pediatric Electrophisiology Society. Radiofrequency catheter ablation for tachyarrhythmias in children and adolescents. $N$ Engl 7 Med

6 Erickson CC, Walsh EP, Triedman JK, Saul JP. Efficacy and safety of radiofrequency ablation in infants and young children $<18$ months of age. Am $\mathcal{f}$ Cardiol 1994; 74:944-7

7 Saul JP, Hulse JE, Walsh EP. Late enlargement of radiofrequency lesions in infant lambs: implications for ablation

procedures in small children. Circulation 1994;90:492-9.
Sánchez C, Benito F, Moreno F. Reversibility of tachycarSánchez C, Benito F, Moreno F. Reversibility of tachycar-
dia-induced cardiomyopathy after radiofrequency ablation of incessant supraventricular tachycardia in infants. Br Heart F 1995;74:332-3.

9 Case CL, Gillette PC, Oslizlok PC, Knick BJ, Blair HL Radiofrequency catheter ablation of incessant, medically resistant supraventricular tachycardia in infants and smal children. $\mathcal{F}$ Am Coll Cardiol 1992;20:1405-10.

10 Saul JP, Hulse JE, De W, Weber AT, Rhodes LA, Lock JE et al. Catheter ablation of accessory atrioventricular pathways in young patients: use of long vascular sheaths, the transseptal approach and a retrograde left posterior parallel approach. $¥ \mathrm{Am}$ Coll Cardiol 1993;21:571-83.

11 Ticho BS, Saul JP, Hulse JE, De W, Lulu J, Walsh EP. Variable location of accessory pathways associated with the permanent form of junctional reciprocating tachycardia and confirmation with radiofrequency ablation. $A m^{\prime}$ Cardiol 1992;70:1559-64.

12 Kugler JD. Radiofrequency catheter ablation for supraventricular tachycardia. Should it be used in infants and tricular tachycardia. Should it be used in
small children? Circulation 1994;90:639-41.

13 Calkins H, Prystowsky E, Carlson M, Klein LS, Saul JP, Gillette PC. Temperature monitoring during radiofreGillette PC. Temperature monitoring during radiofrequency catheter ablation procedures
control. Circulation 1994;90:1279-86.

14 Lesh MD, Coggins DL, Ports TA. Coronary air embolism complicating transseptal radiofrequency ablation of left free-wall accessory pathways. $P A C E$ 1992;15:1105-8. 